\title{
Levamisole in the treatment of cyclical neutropenia
}

\author{
S. J. Proctor \\ M.B., M.R.C.P.
}

\author{
M. M. REID \\ M.B., D.C.H., M.R.C.P.
}

\author{
W. T. Low \\ F.I.M.L.S.
}

\begin{abstract}
Department of Haematology, Royal Victoria Infirmary, Newcastle upon Tyne
\end{abstract}
\begin{abstract}
Summary
A child with cyclical neutropenia was observed before and during treatment with levamisole. Marked clinical improvement occurred while on levamisole. Deterioration occurred after stopping treatment. The improvement was not associated with changes in the neutrophil or monocyte counts, nor did tests of phagocytic cell function convincingly demonstrate improvement while the child was on treatment.
\end{abstract}

\section{Introduction}

Cyclical neutropenia is a rare disease of bone marrow resulting in recurrent infections, especially of the mouth and upper respiratory tract. Verhaegen et al. (1976) suggested previously that levamisole may be of value in the management of this condition. The authors now report the successful use of levamisole in a patient with cyclical neutropenia.

\section{Case report}

A 4-year-old Caucasian girl presented with recurrent episodes of mouth ulceration, swollen neck glands and sore throats. Tonsillectomy shortly after presentation resulted in no improvement. Six months later a diagnosis of Behçet's syndrome was suggested. At that time she required drainage of a cervical abscess. At the age of 8 years she was referred to the dentist because of a persistent gingivitis and a blood count showed marked neutropenia. A detailed history revealed that infections and aphthous ulceration occurred regularly at 3- to 4-week intervals but that between these episodes there were no infective problems. A large amount of time had been lost from school and she was taking antibiotics almost continuously. There was no relevant family history. On examination there was marked cervical and submandibular lymphadenopathy and marked aphthous ulceration. She exhibited dermatographia and had suffered from infantile eczema. After 4 months' observation she was given levamisole $50 \mathrm{mg}$ daily for 2 consecutive days each week for 4 months. There was a marked decrease in the severity, although not in the frequency of infections during the period of treatment. No time now was lost from school and antibiotics were used on only 3 occasions. During the next 6 months, treatment with levamisole was discontinued. There was an immediate deterioration with severe aphthous ulceration and episodes of otitis media and conjunctivitis. One week of school was lost 2 months after stopping treatment. Antibiotic requirements rose.

\section{Methods}

Phagocytic cell function was assessed on 3 occasions before and once after starting levamisole. The nitroblue tetrazolium (NBT) reduction test was based on the method of Segal and Peters (1975). Results were expressed arbitrarily as spectrophotometer units $/ 10^{6}$ neutrophils. Chemotaxis was assessed by a method outlined by Wilkinson (1974). Casein was used as the attractant. Results were expressed as the distance in $\mu \mathrm{m}$ travelled by the leading front of cells through the micropore filter. Random migration was similarly assessed in the absence of attractant. Killing ability was assessed by a method based on that of Goldman and Th'ng (1973). Neutrophils and monocytes were incubated with Candida albicans with a $C$. albicans : phagocyte ratio of $1: 1$. Results were expressed as the percentage of $C$. albicans killed. On every occasion tests were controlled using cells from one of the laboratory staff. A reference range was derived from data obtained from 20 laboratory staff.

Relative proportions and absolute numbers of $T$ and $B$ lymphocytes were assessed by methods previously described (Reid, Craft and Todd, 1977). Reference ranges were derived from data obtained from 14 children aged 1-14 years admitted for elective surgery.

\section{Results}

Figure 1 demonstrates the weekly changes in the neutrophil and monocyte counts before and during 

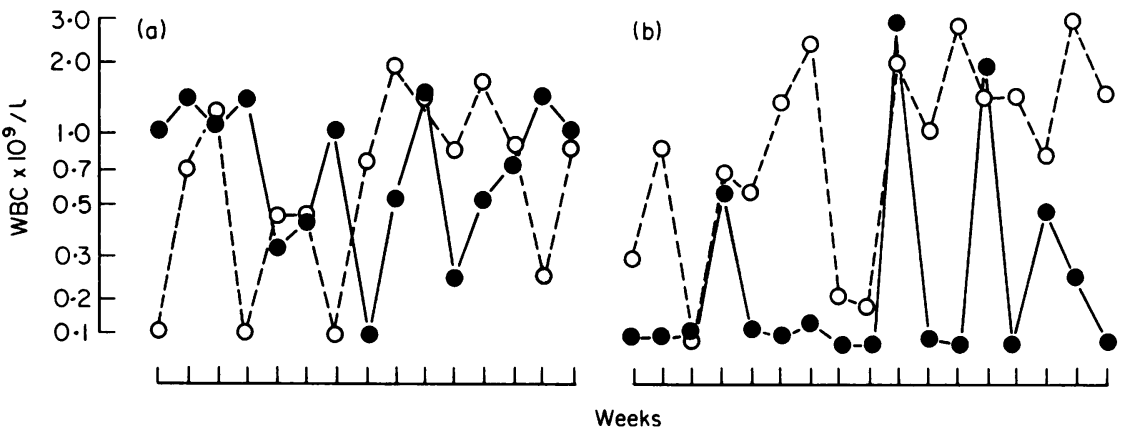

FIG. 1. Absolute polymorph and monocyte counts at weekly intervals (a) before and (b) during treatment with levamisole. Polymorphs $\bigcirc_{---} \mathrm{O}^{\text {; monocytes }}$

treatment with levamisole. On several occasions the monocyte count was high when neutrophils were virtually absent. Periods of marked neutropenia were usually associated with infective episodes. Haemoglobin, platelets, serum and red cell folate and serum immunoglobulins were all within normal limits. There was a relative lymphocytosis at all times.

Table 1 shows the relative proportions and absolute numbers of peripheral blood $T$ and $B$ lymphocytes measured on 2 occasions while off treatment.

Table 2 shows the results of tests of function of phagocytic cells before and during treatment with levamisole. On occasions, adequate numbers of cells for testing were not obtainable.

TABLE 1. Relative proportions and absolute numbers of $\mathrm{T}$ and $\mathrm{B}$ lymphocytes

\begin{tabular}{lllll}
\hline & \multicolumn{2}{c}{ T lymphocytes } & \multicolumn{2}{c}{ B lymphocytes } \\
& $\%$ & No. $\times 10^{9} / 1$ & $\%$ & No. $\times 10^{9} / 1$ \\
\hline Patient & 57 & $2 \cdot 79$ & 50 & 2.43 \\
Normal & 52 & 1.41 & 60 & 1.63 \\
children* & $69 \pm 7$ & $2.26 \pm 0.6$ & $22 \pm 9$ & $0.74 \pm 0.38$ \\
\hline
\end{tabular}

* Results for normal children expressed as mean $\pm s . d$.

\section{Discussion}

The history and physical findings conformed closely with the picture of classical cyclical neutropenia. The pattern of neutropenia lent further support to the diagnosis. In this patient, unlike that reported by Verhaegen et al. (1976), periods of monocytosis did occur before treatment with levamisole. Numbers of circulating $T$ lymphocytes were not significantly different from those observed by the authors in normal children. The relative proportions and numbers of circulating B lymphocytes appeared to be increased. This may be partlyo explained by falsely counting monocytes as Be lymphocytes and would explain why the sum of and B lymphocytes exceeded $100 \%$. Nevertheless; this technical error cannot account for all of the apparent increase in B lymphocytes.

The clinical effect of levamisole is difficult to quantitate. However, the subjective impression of improvement was striking to child, mother and observers, as was the deterioration on stopping treatment. No significant changes occurred in neutrophil and monocyte counts after starting levamisole.

Phagocytic cell function was difficult to assess, primarily because such small numbers of cells were involved. NBT reduction was certainly no less efficient

TABle 2. Phagocytic cell function

\begin{tabular}{|c|c|c|c|c|c|}
\hline & $\begin{array}{l}\text { Nitro blue tetrazolium test } \\
\text { (units } / 10^{6} \text { cells) }\end{array}$ & $\begin{array}{r}\text { Killir } \\
\text { Neutrophils }\end{array}$ & $\begin{array}{l}\text { g ability } \\
\% \\
\text { Monocyte-rich } \\
\text { suspension }\end{array}$ & $\begin{array}{l}\text { Chemotaxis } \\
(\mu \mathrm{m})\end{array}$ & $\begin{array}{c}\text { Random migration } \\
(\mu \mathrm{m})\end{array}$ \\
\hline $\begin{array}{l}\text { Off } \\
\text { Treatment }\end{array}$ & $\begin{array}{r}17 \cdot 82 \\
45 \cdot 00 \\
9 \cdot 52\end{array}$ & $\frac{-}{9}$ & $\begin{array}{r}-20 \\
1\end{array}$ & $\begin{array}{l}85 \\
75 \\
75\end{array}$ & $\begin{array}{l}12 \\
18 \\
22\end{array}$ \\
\hline $\begin{array}{l}\text { On } \\
\text { Levamisole } \\
\text { Normal staff* }\end{array}$ & $\begin{array}{r}8 \cdot 2 \\
12 \cdot 0 \pm 6 \cdot 3\end{array}$ & $\begin{array}{l}25 \\
24 \pm 6\end{array}$ & 19 & 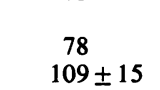 & $\begin{array}{l}20 \\
29 \pm 8\end{array}$ \\
\hline
\end{tabular}

* Results of normal staff are expressed as mean \pm 2 s.d.

- not measured owing to insufficient number of cells 
than for normal neutrophils. On occasions when virtually no neutrophils were present NBT reduction by whole blood was still marked. It is possible that this was being carried out by monocytes. Chemotaxis, while being at the lower end of the ranges observed in normal staff, was not convincingly abnormal. No significant improvement resulted while on treatment. Candidacidal ability of neutrophils was assessed before treatment only once. This was certainly abnormally low. On retesting after starting treatment a normal result was obtained. However, because of technical difficulties with such small numbers of cells, a convincing improvement of function has not been demonstrated. On 2 occasions, once before and once after starting treatment, monocytes in a monocyte-rich mononuclear cell suspension appeared to kill $C$. albicans as effectively as neutrophils.

Lehner, Wilton and Ivanyi (1976) found that levamisole reduced the incidence of aphthous ulceration. Van Eygen et al. (1976) found that it reduced the incidence of recurrent upper respiratory tract infection in children. Symoens and Rosenthal (1977) have suggested that it influences host defences by modulating cell-mediated immune functions. It restores functions of neutrophils, macrophages and $T$ lymphocytes such as phagocytosis, random migration, chemotaxis, migration inhibition, sheep red cell rosette formation, cell-mediated cytotoxicity and lymphokine production. Significant improvement in phagocytic cell function was not convincingly demonstrated in this patient, although clinical improvement did occur. Since levamisole did not alter the absolute neutrophils or monocyte counts in this patient, it might be reasonable to assume that, in addition to neutropenia, there is in these patients an additional as yet unidentified reduction of phagocytic cell function which it is apparently possible to correct with levamisole.

Finally, Huskisson et al. (1976) reported the development of neutropenia in a patient with rheumatoid arthritis being treated with levamisole, and Williams (1976) reported a case of agranulocytosis in a similar patient. Reports of this nature mean that levamisole, in some patients with rheumatic disorders at least, does have important and potentially hazardous side effects. There was no suggestion of more severe neutropenia in this patient while she was taking the drug. Levamisole may be an effective and safe method of treating this rare but distressing condition.

\section{Acknowledgment}

M.M.R. was supported by a grant from the Tyneside Leukaemia Research Association.

\section{References}

Goldman, J.M. \& TH'NG, K.H. (1973) Phagocytic function of leucocytes from patients with acute myeloid and chronic granulocyte leukaemia. British Journal of Haemato$\log y, 25,279$.

Huskisson, E.C., Diepre, P.A., Scott, J., Trapnell, J., Balme, H.W. \& Willoughby, D.A. (1976) Immunostimulant therapy with levamisole for rheumatoid arthritis. Lancet, i, 393.

Lehner, T., Wilton, J.M.A. \& IVanyi, L. (1976) Double blind crossover trial of levamisole in recurrent aphthous ulceration. Lancet, ii, 926.

ReID, M.M., Craft, A.W. \& Todd, J.A. (1977) Serial studies of numbers of circulating $T$ and $B$ lymphocytes in children with acute lymphoblastic leukaemia. Archives of Disease in Childhood. 52, 245.

Segal, A.W. \& Peters, T.J. (1975) The nylon column dye test: a possible screening test of phagocytic function. Clinical Science and Molecular Medicine, 49, 591.

Symoens, J. \& Rosenthal, M. (1977) Levamisole in the modulation of the immune response: the current experimental and clinical state. Journal of the Reticuloendothelial Society, 21, 175.

VAN Eygen, M., ZnAmensky, P.Y., Heck, E. \& Raymaekers, I. (1976) Levamisole in prevention of recurrent upper respiratory tract infections in children. Lancet, $\mathbf{i}, 382$.

Verhaegen, H., DeCrée, J., DeCock, W. \& Brugmans, J. (1976) Levamisole treatment of a child with severe aphthous stomatitis, and neutropenia. Postgraduate Medical Journal, 52, 511.

WILKINSON, P.C. (1974) Chemotaxis and Inflammation. Edinburgh and London. Churchill Livingstone.

Williams, I.A. (1976) Levamisole and agranulocytosis. Lancet, i, 1080. 